SPOR BILIMLERI ARASTTIRMALARI DERGISI
Journal of Sport Sciences Researches
JSSR
http://dergipark.gov.tr/jssr
ISSN: $2548-0723$

\title{
Oyun ve Motor Beceri Eğitimi Sırasında 4 Yaş Çocuklarda Gözlenen Davranış Bozukluklarının Önlenmesinde Çarpı Stratejisinin Etkisi*
}

\author{
Fatma İlker KERKEZ ${ }^{1 \dagger}$ \\ ${ }^{1}$ Muğla Sıtkı Koçman Üniversitesi, Spor Bilimleri Fakültesi, Muğla, ORCID iD: 0000-0002-5485-1834.
}

$\ddot{\mathbf{O} z}$

Okul öncesi dönemde motor gelişimi desteklemeye yönelik yapılandırılmış oyun ve motor beceri içerikli programların çocuklarda fiziksel aktiviteyi artırmak suretiyle motor, sosyal, zihinsel ve duygusal sağlığı desteklediği bilinmektedir. Bu dönemdeki çocuklarda gözlenebilen ve davranış bozukluğu olarak adlandırılan inatlaşma, kavgacılık, utangaçlık, ağlama, saldırganlık gibi davranışlar oyun ve motor beceri eğitimi sırasında da gözlenebilmektedir. Bu çalışmanın amacı 4 yaş grubu çocuklarda motor gelişimi desteklemeye yönelik yapılandırılmış oyun ve motor beceri eğitimi programı sırasında çarpı stratejisi yoluyla davranış bozukluklarının azaltılması ve çocuklara olumlu değerlerin kazandırılmasıdır. Bu çalışma eylem araştırması deseninde nitel araştırmadır. Çalışma kapsamında toplam 12 çocuk 28 hafta süreyle haftada iki gün motor gelişimi desteklemeye yönelik yapılandırılmış oyun ve motor beceri eğitimine katılmıştır. Çocuklarla her çalışmadan önce istenmeyen davranışlar daha yapılmadan iki elin işaret parmaklarıyla hayır anlamında çarpı hareketi yapılarak; ağlamak çarp1, yüksek sesle bağırmak çarpı, arkadaşını itmek çarpı şeklinde tekrar edilmiştir. Motor beceri eğitimi ve oyunlar sırasında bu davranışlardan birini gösteren olursa sadece çarpı işareti yapılarak ikaz edilmiştir, davranışı sürdürürse kenara alınıp istenmeyen bir davranış yaptığı için beklediği açıklandıktan sonra tekrar oyuna dâhil edilmiştir. Çocuklarda çarpı stratejisinin etkili olup olmadığı sınıf öğretmenlerine ve ailelere yarı yapılandırılmış görüşme ile sorulmuştur (aile=12, öğretmen=3 toplam=15). Veriler betimsel analiz ile değerlendirilmiștir. Katılımcı görüșlerine göre çarpı stratejisi 4 yaş grubu çocuklarda davranış bozukluklarını azaltmada ve olumlu değer kazandırmada etkili görülmüştür. Çocuklardaki olumlu davranışlar öğretmenleri ve aileleri tarafından fark edilmiştir. Oyun ve hareket eğitimi sırasında gözlenen davranış bozukluklarını azaltmada çarpı stratejisinin etkililiği başka gruplarda sınanabilir.

\section{Orijinal Makale}

Yayın Bilgisi

Gönderi Tarihi: 05.01.2018

Kabul Tarihi: 11.06.2018

Online Yayın Tarihi: 30.06.2018

DOI: $10.25307 /$ jssr. 375487
Anahtar kelimeler:

Okul öncesi, oyun, motor beceri, çocuk davranış bozuklukları

\footnotetext{
* Bu çalışma 23-26 Kasım 2017 tarihlerinde Manisa'da gerçekleştirilen Dünya Spor Bilimleri Araştırmaları Kongresi’nde sözel bildiri olarak sunulmuştur.

† Sorumlu Yazar E-mail: kerkez.f@gmail.com, Tel: +905319915100.
} 
İlker Kerkez, F. (2018). Oyun ve motor beceri eğitimi sırasında 4 yaş çocuklarda gözlenen davranış bozukluklarının önlenmesinde çarpı stratejisinin etkisi. Spor Bilimleri Araştırmaları Dergisi, 3(1), 54-63.

\title{
The Influence of Two Fingers Crossing in X Form Strategy in the Prevention of Behavioral Disorders Observed in 4-Year-Old Children During Motor Skill Intervention
}

\begin{abstract}
Original Article

As known motor skill intervention programs may have an important role in preschoolers attaining motor skill proficiency as the basis for a physically active lifestyle and to profit from a variety of motor, social, emotional and cognitive health benefits. Behaviors such as stigmatization, confrontation, shyness, crying, aggression that can be observed in children during this period and which is called behavioral disorders can also be observed during motor skills intervention. The aim of this study is to reduce behavioral disorders and gain positive values for children by testing Two Fingers Crossing in X Form Strategy during a motor skill intervention in children 4 years of age. This study is a qualitative research in action research design. A total of 12 children participated in the motor skills intervention for twice a week for 28 weeks. Before each work we made two fingers crossing in $\mathrm{x}$ form means no to the children and repeated crying no, speaking loudly no, pushing a friend no. During the designed motor skill intervention class if one of the children showed these behavioural disorders he or she warned via making two fingers crossing in $\mathrm{X}$ form quietly, still he or she insisted that behavior was taken out of the play, was kept for a couple minutes and was explained why he or she was taken from the play. The question of whether the multiplication strategy was effective in children was asked by classroom teachers and families with semi-structured interviews (family $=12$, teacher $=3$ total $=15$ ). The data were evaluated by descriptive analysis. According to the participant's opinion, Two Fingers Crossing in X Form Strategy was seen to be effective in reducing the behavioral disturbances in the 4-year-old children and in providing positive moral values. Positive behaviors in children have been recognized by teachers and their parents. The effectiveness of the Two Fingers Crossing in X Form Strategy of reducing behavioral disorders observed during designed motor skill intervention can be tested in other groups.
\end{abstract}

\section{GíRiş}

Okulöncesi dönemde temel motor becerilerin desteklenmesi çocukların ileriki dönemlerde daha karmaşık sportif becerileri gerçekleştirmeleri için gereklidir. Çünkü bu beceriler yürüme ve kavrama gibi kendiliğinden ortaya çıkan filogenetik beceriler değildir. Temel motor beceriler genellikle koşu, gallop, seksek, sıçrama, yana kayma gibi lokomotor becerilerle, atma, yakalama, vurma gibi manipulatif beceriler olarak gruplanır. Bu beceriler tüm oyunlarda, spor dallarında amaca yönelik olarak farklı şekillerde kullanılır. Temel motor becerilerde ustalaşma okulöncesi dönemde kazanılmalıdır, bu sayede bireylerde yetenek ve ilgileri doğrultusunda yaşam boyu hareketlilik ve hatta profesyonel spor yaşamı sağlanabilir. Literatürde motor becerileri destekleyici müdahale çalışmalarının bazı değişkenlere olumlu etkisinin kaydedildiği pek çok çalışma mevcuttur (Bellows, Davies, Anderson ve Kennedy, 2013; Deli, Bakle ve Zachopoulou, 2006; Donath ve diğ., 2015; Hardy ve diğ., 2010; Iivonen, Sääkslahti ve Nissinen, 2011; Ling, Robbins, Wen ve Peng, 2015; Pless, Carsson, Sundelin ve Persson, 2000; Riethmuller, Jones ve Okely, 2009; Robinson ve Goodway, 2009). Ancak bu çalışmaların hiç birinde motor becerileri destekleyici müdahale çalışmalarının etkililiğini belirleyebilecek durumlardan söz edilmemiştir. Bu durumlardan biri okulöncesi çocukların istenmeyen davranışlarıdır. Okulöncesi dönemdeki çocuklar toplumsal kuralları anlamaları gereken sürekli bir süreçten geçerken aynı zamanda daha bağımsız davranmayı ister ve kuralları kabullenmeleri çok kolay olmaz. Bu dönemde inatlaşma, kavgacılık- saldırganlık, aşırı hareketlilik, utangaçlık, endişeli-ağlamaklı olmak gibi davranış bozuklukları gözlenebilmektedir. Bu tür davranışların mazur görülmesi ve önlem alınmaması durumunda 
İlker Kerkez, F. (2018). Oyun ve motor beceri eğitimi sırasında 4 yaş çocuklarda gözlenen davranış bozukluklarını önlenmesinde çarpı stratejisinin etkisi. Spor Bilimleri Araştırmaları Dergisi, 3(1), 54-63.

çocukların ilerde karşılaşabileceği akademik ve sosyal sorunların önüne geçilmesi her geçen gün daha da güçleşebilir. Davranış bozukluklarının belirlenmesi ve mücadele sürecinde, yardım gereksinimi çocuğun kendisi tarafından gelemeyeceğine göre sorumluluk aile ve öğretmenlerdedir. Bu tür davranışları görmezden gelmek, önlem almamak ya da savunmak çocuklarda hem kendileri hem de toplum için ileriye yönelik riskler oluşturmaktadır. Davranış bozuklukları kalıcı hale gelmeden en etkili strateji kullanılarak çocuğun toplum hayatına kazandırılması önem arz etmektedir.

Literatürde okulöncesi dönemde sınıf ortamında görülen davranış bozuklukları ve öğretmenlerin bu davranışlarla mücadelede tercih ettikleri stratejileri ele alan çalışmalar mevcuttur. İkiz ve diğ., (2016) sınıf ortamında en sık görülen problem davranışları nitel veri toplama formu oluşturarak öğretmen ifadelerine göre; "yalan söyleme", "yemek seçme/yemeye isteksizlik", "ebeveynden ayrılma korkusu", "kıskançlık", "inatçıllk" "saldırganlık", "konuşma bozukluğu", "alt ıslatma/dışkı kaçırma", "tırnak yeme", "aşırı etkinlik ve dikkat eksikliği", "karanlıktan korkma", "çalma", "parmak emme" ve "tikler" olarak sıralamıştır. Uysal ve diğ., ise (2010) okulöncesinde istenmeyen davranışları katılımcı olmayan gözlem tekniği ile kaydettikleri çalışmada; sınıfın dikkatini dağıtma ve etkinliği bölme, söz kesme, gürültü etme, dolaşma, arkadaşı ile dalga geçme, şikâyet etme, sataşma, vurma ve kavga etme, materyallere zarar verme, yönerge ve kurallara uymama olarak belirtmişlerdir. Sınıf ortamında görülen problem davranışlar literatürde özetlenmişken yapılandırılmış oyun, hareket ya da motor beceri destekleyici programlar sırasında ortaya çıkan davranış bozukluklarını ele alan bir çalışmaya rastlanmamıştır. Sınıf ortamında davranış bozukluğu gösteren çocuklar sınıf ortamından ayrı olarak yapılan oyun ve motor beceri destekleyici eğitimlerde de çeşitli şekillerde davranış bozuklukları gösterebilmektedir. Hatta sınıf ortamında davranış bozukluğu göstermeyen bazı çocuklar daha rahat hareket edebildikleri oyun ortamında beklenmedik davranışlar gösterebilmektedir. Bu noktada uygulanması gereken pedagojik öneriler bulunmaktadır. Bunlar; çocukları isimle çağırma, başlama bitirme ritüelleri, bireysel geri bildirim ve kurallardır. Kurallar yardım ve destek olarak görülmeli ve çocukların uyum sağlamalarını kolaylaştırmalıdır. Neyi yapıp neyi yapmayacağını bilmeyen çocuklar kendilerini güvende hissetmezler. Sadece yapılmaması gerekenler değil yapılması gerekenler de kurala bağlanmalıdır (Roth ve diğ., 2016).

\section{Çarpt Stratejisi}

4 yaş grubu çocuklarda toplumsal kurallar ve ahlak olgusu gelişmekte olduğundan kurallar söylenmeden yanlış olduğunu bilemeyebilirler. Bu nedenle bu çalışmada çocuklarla her çalışmadan önce istenmeyen davranışlar daha yapılmadan tekrar edilmiştir. Çarpı denmesinin nedeni işaret parmaklarını üstüste getirerek "hayır veya yanlış" anlamında çarpı hareketi yapılmasıdır. Bu hareket genel anlamda yanlış, matematikte on ve Japonca'da geri almak anlamında kullanılmaktadır (https://www.shutterstock.com/tr/image-photo/two-fingerscrossing-x-form-isolated-505655167, Erişim tarihi: 27.10.2017). Strateji ise; "önceden belirlenen bir amaca ulaşmak için tutulan yolların ve uygulanan yöntemlerin tümü” olarak tanımlanır ve bu çalışmada da yöntem anlamında kullanılmıştır. Sonuç olarak çarpı stratejisi; oyun ve motor beceri eğitimi başında çocuklarla daire düzeninde oturarak istenmeyen 
İlker Kerkez, F. (2018). Oyun ve motor beceri eğitimi sırasında 4 yaş çocuklarda gözlenen davranış bozukluklarının önlenmesinde çarpı stratejisinin etkisi. Spor Bilimleri Araştırmaları Dergisi, 3(1), 54-63.

davranışların hayır anlamında (yanlış anlamında) çarpı hareketi yapılarak tekrarlanması ile başlar; ağlamak çarpı, bağırmak çarpı, başkasının sırasını almak çarpı, vurmak-itmek çarpı. $\mathrm{Bu}$ seremoninin ardından çocuklarla oyun ve motor beceri eğitim programına geçilmiştir. Oyun ve motor becerilerin uygulanması sırasında istenmeyen davranışlardan birini gösteren olursa çarpı işareti yapılarak ve örneğin ağlamak çarpı denilerek ilgili çocuk ikaz edilmiştir. Buna rağmen ağlamayı sürdüren çocuk olursa kenara alınmış ve ağlaması sona erene kadar bekledikten sonra, çarpı içeren davranışlardan birini yaptığı için beklediği açıklanmıştır ve tekrar programa dâhil edilmiştir. Bu yöntem Roth ve diğ. (2016) tarafindan da tekrarlayan davranışlarda artan sürelerle tavsiye edilmektedir. Bu uygulamanın amacı çocukların istenmeyen davranışları anlaması, başkalarını koruma, saygı, işbirliği, dürüstlük gibi olumlu değerleri kazanmasıdır. Buna ek olarak çocukların iyi yaptıkları her davranış için alkışlanmış, aferin, bravo, harika gibi sözler söylenmiş ve beşlik (çak) hareketi yapılmıştır.

$\mathrm{Bu}$ çalışmanın amacı oyun ve motor beceri eğitimi sırasında görülen davranış bozukluklarını azaltmak ve olumlu davranış kazandırmak için yukarda açıklanan çarpı stratejisinin etkililiği araştırmaktır.

\section{YÖNTEM}

\section{Araştırma Modeli}

$\mathrm{Bu}$ çalışma eylem araştırması deseninde nitel bir çalı̧̧adır. Nitel yöntemle tasarlanmış araştırmalarda ele alınan konu hakkında derin bir kavrayışa ulaşma çabası vardır. Bu yönüyle araştırmacı bir kâşif gibi hareket ederek ilave sorularla gerçekliğin izini sürer ve muhatabının öznel bakış açısına önem verir (Karataş, 2015). Eylem araştırması, eğitim örgütlerinde çalışanların (öğretmen, yönetici, uzman vb.) kendi durumlarına özgü problemlerine çözüm üretmede veya kendilerini yenileyebilmeleri için kullanabilecekleri araçlardan biridir. Eylem araştırması, okulda veya sınıfta karşılaşılan sorunların çözümü için kullanılabileceği gibi okul veya ders programların iyileştirilmesinde de kullanılabilir (Beyhan, 2013).

\section{Çalışma Grubu}

Çalışma grubu Muğla Sıtkı Koçman Üniversitesi (MSKÜ) Gündüz Bakımevinde eğitim alan 4 yaş grubu sınıfındaki sağlıklı tüm çocuklar ile aileleri ve öğretmenleridir. Araştırmada örneklem belirleme türü olarak kolay ulaşılabilir örnekleme benimsenmiştir. MSKÜ Gündüz Bakımevinde eğitim gören 12 çocuk ( 8 kız, 4 erkek) motor beceri eğitimine yönelik yapılandırılmış oyun ve motor beceri eğitim programına dâhil edilmiştir. Program sırasında çarpı stratejisi uygulanmış ve çocukların davranışlarına etkisi ailelere $(n=12)$ ve öğretmenlerine ( $\mathrm{n}=3$ ) sorulmuştur (toplam 15). Katılımcı ebeveyn ve öğretmenlere ait yaş, boy, kilo, eğitim seviyesi bilgileri Tablo 1'de sunulmuştur. 
İlker Kerkez, F. (2018). Oyun ve motor beceri eğitimi sırasında 4 yaş çocuklarda gözlenen davranış bozukluklarını önlenmesinde çarpı stratejisinin etkisi. Spor Bilimleri Araştırmaları Dergisi, 3(1), 54-63.

Tablo 1. Ebeveyn ve öğretmenlere ait demografik bilgiler.

\begin{tabular}{llccc}
\hline Değişkenler & Anne (n=12) & Baba (n=12) & $\begin{array}{c}\text { Öğretmenler (n=3) } \\
\text { Hepsi kadın }\end{array}$ \\
\hline 1- Yaş (yıl) & & $34.7 \pm 5.1$ & $40.1 \pm 5.5$ & $36 \pm 6.6$ \\
2- Boy (cm) & $164 \pm 6.11$ & $176 \pm 7.0$ & $157 \pm 4.0$ \\
3- Kilo (kg) & & $60.91 \pm 8.4$ & $84 \pm 8.75 \mathrm{~kg}$ & $58.5 \pm 8.0$ \\
\hline & & $\%(\mathrm{n})$ & $\%(\mathrm{n})$ & $\%(\mathrm{n})$ \\
\hline \multirow{4}{*}{ 4- Eğitim } & Doktora & $16.7(2)$ & $66.7(8)$ & - \\
& Yüksek lisans & $25(3)$ & $8.3(1)$ & - \\
& Lisans & $50(6)$ & $8.3(1)$ & $33.3(1)$ \\
& Lise & - & $8.3(1)$ & $66.7(2)$ \\
& Ortaokul & - & - & - \\
\hline
\end{tabular}

\section{Veri Toplama Aracı}

Çalışmada uygulanan çarpı stratejisinin etkililiğinin çocuklar üzerine etkisini tespit etmek için araştırmacı tarafından geliştirilen yarı yapılandırılmış görüşme formu kullanılarak veli ve öğretmenler ile yüz yüze görüşme yapılmıştır. Görüşmeler araştırmacı tarafından yazı ile kayıt altına alınmıştır.

\section{İşlem Yolu}

Çalışma Muğla Sıtkı Koçman Üniversitesi (MSKÜ) Gündüz Bakımevinde 2015-2016 eğitimöğretim yılında gerçekleştirilmiştir. Çalışma için MSKÜ Rektörlüğünden ve ailelerden izin alınmıştır. Oyun ve motor beceri eğitimi programı 28 hafta süreyle haftanın iki günü günde bir saat (56 saat) uygulanmıştır. Tüm program bakımevi müdiresi ve öğretmenlerin gözetiminde gerçekleştirilmiştir. Programda denge, lokomotor ve manipulatif becerileri geliştirmeye yönelik oyun ve istasyonlar kullanılmıştır. Bu arada çalışmanın amacına yönelik olarak çarpı stratejisi uygulanmıştır.

\section{Verilerin Analizi}

Çalışmada uygulanan stratejinin etkililiği betimsel analiz ile değerlendirilmiştir. Betimsel analiz, derinlemesine analiz gerektirmeyen verilerin işlenmesinde kullanılır (Yıldırım ve Şimşek, 2008). Elde edilen verilerin özgün şekline mümkün olduğunca bağlı kalınarak ve gerektiğinde katılımcıların ifadelerinden doğrudan alıntı yapılarak betimsel bir yaklaşımla verilerin sunulmasıdır. 
İlker Kerkez, F. (2018). Oyun ve motor beceri eğitimi sırasında 4 yaş çocuklarda gözlenen davranış bozukluklarını önlenmesinde çarpı stratejisinin etkisi. Spor Bilimleri Araştırmaları Dergisi, 3(1), 54-63.

\section{BULGULAR}

\section{Motor Beceri Eğitimi Sırasında Kaydedilen Davranış Bozukluklarına İlişkin Bulgular}

Toplam 56 saat süren oyun ve motor beceri eğitimi sırasında çocuklarda gözlenen davranış bozuklukları kaydedilmiş ve görülme sıklığına göre Tablo 2'de sıralanmıştır.

Tablo 2. Oyun ve Motor Beceri Eğitimi sırasında gözlenen davranış bozuklukları.

\begin{tabular}{|c|c|}
\hline Ağlama & $\begin{array}{ll}\text { - } & \text { Oyun sırasında çarpışma ya da düşme gibi nedenlerden } \\
\text { - } & \text { Uygulanan görevi başaramadığı için } \\
\text { - } & \text { Arkadaşı kendisini rahatsız ettiği için } \\
\text { - } & \text { Oyunda ebelendiği için kenara geçmesi gerekiyorsa }\end{array}$ \\
\hline Sızlanma ve Şikâyet & $\begin{array}{ll}\text { - } & \text { Arkadaşı kendisini rahatsız ettiği için } \\
\text { - } & \text { Arkadaşı görevleri tam yapmadığ için } \\
\text { - } & \text { Yorulduğu için } \\
\text { - } & \text { Bir yeri acıdığı için } \\
\end{array}$ \\
\hline $\begin{array}{l}\text { Dinlememe-Başına } \\
\text { buyruk davranma }\end{array}$ & $\begin{array}{l}\text { - Anlatılan oyunları ya da görevleri dinlememe } \\
\text { - Uygulanan görevler yerine kendi istediğini yapma } \\
\text { - Uygulanan görev yerine başka oyunlar teklif etme } \\
\text { - Çarpı dendiğinde göz teması kurmaktan kaçınma ve kenara } \\
\text { geçmeyi reddetme }\end{array}$ \\
\hline $\begin{array}{l}\text { Aşırı hareketlilik- } \\
\text { Dikkat eksikliği }\end{array}$ & $\begin{array}{ll}\text { - } & \text { Anlatılan oyunları ya da görevleri dinlemeyip sürekli koşturma } \\
\text { - } & \text { Dikkat eksikliği nedeniyle görevleri eksik ya da hatalı yapma }\end{array}$ \\
\hline $\begin{array}{l}\text { Şiddet içeren } \\
\text { davranışlar }\end{array}$ & $\begin{array}{ll}\text { - } & \text { Arkadaşlarına vurma, itme, 1sırma, tükürme } \\
\text { - } & \text { Oyunla ilgili istasyonları yıkma, devirme, bozma }\end{array}$ \\
\hline
\end{tabular}

Tablo 2'de de görüldüğü gibi oyun ve motor beceri eğitimi içerikli hareketler sırasında 4 yaş grubu çocuklarda en sık gözlenen istenmeyen davranış ağlama olmuştur. Çocukların her durumda ağlamaya müsait oldukları ve tepkilerini ağlayarak dile getirdikleri gözlenmiştir. Oyun sırasında düşerse ya da çarpışırlarsa ciddi bir çarpışma olmadığ 1 halde ve bir yeri gerçekten acımadığı halde hemen ağlamaya başladıkları ve özel ilgi bekledikleri görülmüştür. İkinci sırada sızlanma ve şikâyet gelmektedir. Çocuklar sıklıkla birbirlerini şikâyet etmekte, yapılanlardan ya da yapılmayanlardan dolayı sızlanmaktadır. Üçüncü sırada ilk iki davranışa oranla oldukça az olsa da dinlememe-başına buyruk davranma gelmektedir. $\mathrm{Bu}$ davranış erkek çocuklarda daha fazla olmakla birlikte anlatılan görevleri dinlememe, kendi istediğini yapmaya çalışma, çarpı dendiğinde göz teması kurmaktan kaçınma ve kenara geçmeyi reddetme biçimde gözlenmiştir. Daha sonra ise aşırı hareketlilik-dikkat eksikliği ve şiddet içeren davranış bozuklukları kaydedilmiştir. Aşırı hareketli çocuklar sürekli koşturmak, görevleri eksik ya da hatalı yapmak şeklinde; şiddet eğilimli çocuklar ise kurulan istasyonları yıkmak, arkadaşlarına vurma, itme, tükürme şeklindeki davranış bozukluklarını göstermiştir.

\section{Çarpı Stratejisinin Etkiliğine İlişkin Bulgular}

Katılımcılarla yapılan yarı yapılandırılmış görüşme sonucunda çarpı stratejisi hakkındaki görüşleri betimsel analiz kullanılarak değerlendirilmiştir. Katılımcıların geneli yapılan çalışmaların hem motor gelişime hem davranış değişikliğine katkı sağladığını düşünmektedir. Buna ilişskin katılımcı görüşleri aşağıdaki gibidir (E: ebeveyn): 
İlker Kerkez, F. (2018). Oyun ve motor beceri eğitimi sırasında 4 yaş çocuklarda gözlenen davranış bozukluklarının önlenmesinde çarpı stratejisinin etkisi. Spor Bilimleri Araştırmaları Dergisi, 3(1), 54-63.

Olumsuz davranışlarda çarpıyı hayatımızın her anında uygulamaya başladık ve olumlu-olumsuz davranışlar büyük oranda oturdu (E1).

İnatlaşma davranışında azalma görmekteyiz. Hatalı olduğunda özür dilemeye başladı, konuşma becerisi arttı (E2)

Denge ve konsantrasyon sağlamada gelişme görüyorum, kurallara uyma ve davranışların kontrolü ile öfke kontrolünde olumlu davranışlar sergiliyor (E3).

İstenmeyen davranışlar için koyduğunuz kurallar için teşekkür ederiz (ağlamak, bağırmak çarpı diyerek eliyle gösteriyor (E4).

Hareket ve oyun olan günler okula daha istekli geliyor. Yaptığınız aktiviteleri evde anlatıyor, çok memnun (E5).

Öğretmenlerin tamamı da çarp1 stratejisinin oyun ve hareket programı sırasında çocuklarda davranış problemlerini azalttığını bu süreçte motor gelişimlerinin olumlu şekilde değiştiği ve da uyguladıklarını belirtmişlerdir. Görüldüğü gibi katılımcılar çarpı stratejisini davranış bozukluklarını önlemede ve olumlu değer kazandırmada etkili bulmuştur.

\section{TARTIŞMA ve SONUÇ}

$\mathrm{Bu}$ çalışma eylem araştırması deseninde nitel araştırma olup, 4 yaş grubu çocuklarda motor gelişimi desteklemeye yönelik oyun ve motor beceri eğitimi programı sırasında çarpı stratejisinin denenmesi yoluyla davranış bozukluklarının azaltılması ve çocuklara olumlu değerlerin kazandırılması hedeflenmiştir. Çalışma kapsamında toplam 12 çocuk 28 hafta süreyle haftada iki gün motor gelişimi desteklemeye yönelik yapılandırılmış oyun ve motor beceri eğitimine katılmıştır. Yapılandırılmış oyun ve motor beceri eğitiminin uygulandı̆̆ araştırmalarda genellikle motor beceri düzeylerindeki değişim (lokomotor beceriler, manipulative beceriler) çeşitli yöntemlerle (TGMD, TGMD-2, MoTB 3-7, BOT-2SF, MABC-2, pedometer) ölçülerek ölçümler arasındaki farka bakılmak suretiyle değerlendirme yapılmaktadır. Wick ve diğ., (2017) bu değerlendirmelerin düşük kalitede kanıtlara dayandığ ve hemen müdahale sonrası ölçümlerden ziyade uzun vadeli etkilerin değerlendirilmesi gerektiğini belirtmişlerdir. Çalışmamızda ise oyun ve hareketler sırasında davranış bozukluklarının azaltılmasına yönelik bir yöntem kullanılarak farklı bir boyut kazandırılmıştır. Çarpı stratejisinde kullanılan uygulama öncesi kuralların belirlenmesi ve istenmeyen davranış gözlendiğinde çocuğun belirli sürelerde oyun dışına alınması Roth ve diğerlerinin (2016) önerdiği pedagojik yöntemle uyumludur.

Uysal ve diğ., (2010) okulöncesi öğretmenlerinin çocukların istenmeyen davranışları karşısında uyguladıkları stratejileri gözlem yoluyla araştırdıkları çalışmada; öğretmenlerin en çok kullandıkları stratejinin "sözel uyarı (Kuralı hatırlatma, soru sorma, ismiyle uyarma, işaretle uyarma)", "sözel olmayan uyarı (Göz kontağı kurma, sessiz kalma, dokunarak uyarma)" ve "1. Tip ceza" (Azarlama, gözdağı verme, cezayı hatırlatma) olduğu 
İlker Kerkez, F. (2018). Oyun ve motor beceri eğitimi sırasında 4 yaş çocuklarda gözlenen davranış bozukluklarını önlenmesinde çarpı stratejisinin etkisi. Spor Bilimleri Araştırmaları Dergisi, 3(1), 54-63.

kaydedilmiştir. Çalışmamızda kullanılan çarpı stratejisi sözel uyarı yani kuralı hatırlatma ile benzerlik göstermektedir. Ancak çarpı stratejisinde her çalışma öncesi çarpı içeren davranışlar tekrar edilmiştir ve avantajı diğer stratejilere gerek duyulmadan problem davranışların oyun alanı içinde konuşmaya ve zaman kaybına mahal vermeden çözülebilmiş olmasıdır. Özdemir ve Tepeli (2016), 12 okul öncesi öğretmeninin katıldığı çalışmalarında; okul öncesi öğretmenlerin saldırgan davranışlarla baş etmede kullandıkları stratejiler; sözel uyarı, II. tip ceza verme, görmezden gelme, çözüm yolu sunma, bilişsel ikna, çocuğun yerini değiştirme/mola verme, I tip ceza verme, rehberlik sağlama, sorunu anlama, yardım alma ve empati olarak belirlenmiş̧tir. Araştırma bulguları incelendiğinde hem görüşme hem de gözlem sonuçlarına göre öğretmenlerin saldırgan davranışlarla baş etmede en çok sözel uyarıyı kullandıkları saptanmıştır. Özbey (2010) okul öncesi çocuklarda uyum ve davranış problemleriyle başa çıkmada ailenin rolü üzerinde durmuştur. Bu çalışmanın sınırlılığı ailelerin stratejiyi günlük yaşamda kullanmasının istenmemiş olmasıdır. İkiz ve diğ., (2016) 20 kadın okul öncesi öğretmeni ile yaptıkları görüşme neticesinde sınıflarında en sık karşılaştığı problem davranışlar sırasıyla yalan söyleme; yeme alışkanlığı sorunları, ayrılık kaygısı, kıskançlık, konuşma bozuklukları ve tırnak yeme olarak kaydetmişlerdir. Problem davranışların nedenleri olarak ailesel, gelişimsel sıkıntıların yanı sıra kişilik ve ilişki kurma sorunları; yeni ve alışılmadık durumla baş edememe ve kitle iletişim araçlarının etkisi ifade edilmiştir. Okul öncesi öğretmenlerin problem davranışlarla baş etmede ailelerle işbirliğine ve profesyonel yardıma ihtiyaç duydukları üzerinde durulmuştur. Sonuç olarak, 4 yaş grubu çocuklarda oyun, hareket ve motor beceri uygulamaları sırasında çarpı stratejisinin uygulanması ağlamak, bağırmak, diğer arkadaşlarını itmek, uygulama yapmasını engellemek gibi davranış bozukluklarının önlenmesinde ve olumlu davranışlar kazandırmada etkili sonuçlar vermiştir. Çocuklardaki olumlu davranışlar öğretmenleri ve aileleri tarafından fark edilmiştir.

Sonuç olarak, çarpı stratejisi 4 yaş grubu çocuklarda oyun ve motor beceri uygulamaları sırasında sıklıkla görülen ağlama, sızlanma-şikâyet ve dinlememe - başına buyruk davranma şeklindeki davranış bozukluklarını önlemede etkili olmuştur. Bu çalışmanın araştırmacılara ve ülkemizde okulöncesi dönemdeki çocuklarla oyun, spor, motor beceri çalışmaları yapan öğretmen, aile ve antrenörlere kullanabilecekleri bir yöntem sunarak literatüre katkı sağladığı düşünülmektedir. Çarpı stratejisinin etkililiğinin artması için ailelerin evde ve öğretmenlerin diğer derslerde ortak hareket edilmesi gerektiği aşikârdır. Gelecek çalışmalarda işbirliği istenebilir ve farklı gruplarda çalışılabilir. 
İlker Kerkez, F. (2018). Oyun ve motor beceri eğitimi sırasında 4 yaş çocuklarda gözlenen davranış bozukluklarının önlenmesinde çarpı stratejisinin etkisi. Spor Bilimleri Araştırmaları Dergisi, 3(1), 54-63.

\section{KAYNAKLAR}

Bellows, L.L., Davies, P.L., Anderson, J., \& Kennedy, C. (2013). Effectiveness of a physical activity intervention for Head Start preschoolers: a randomized intervention study. The American Journal of Occupational Therapy, 67(1), 28-36. DOI:10.5014/ajot.2013.005777.

Beyhan, A. (2013). Eğitim örgütlerinde eylem araştırması. Bilgisayar ve Eğitim Araştırmaları Dergisi, 1(2), 6589.

Deli, E., Bakle, I., \& Zachopoulou, E. (2006). Implementing intervention movement programs for kindergarten children. Journal of Early Childhood Research, 4(1), 5-18. DOI:10.1177/1476718X06059785.

Donath, L., Faude, O., Hagmann, S., Roth, R., \& Zahner, L. (2015). Fundamental movement skills in preschoolers: a randomized controlled trial targeting object control proficiency. Child Care Health Development, 41(6), 1179-87. DOI: 10.1111/cch.12232.

Hardy, L.L., King, L., Kelly, B., Farrell, L., \& Howlett, S. (2010). Munch and move: evaluation of a preschool healthy eating and movement skill program. International Journal of Behavioral Nutrition and Physical Activity, 7(1), 80-91. DOI: 10.1186/1479-5868-7-80.

Iivonen, S., Sääkslahti, A., \& Nissinen, K. (2011). The development of fundamental motor skills of four- to five year old preschool children and the effects of a preschool physical education curriculum. Early Child Development and Care, 181(3), 335-43. https://doi.org/10.1080/03004430903387461.

İkiz, F.E., Mete Otlu, B., ve Ekinci Vural, D. (2016). Erken çocukluk döneminde görülen problem davranışlar: Öğretmenlerin değerlendirmesi. Mehmet Akif Ersoy Üniversitesi Sosyal Bilimler Enstitüsü Dergisi, 8(17), 216-229. DOI: $10.20875 / \mathrm{sb} .35952$.

Karataş, Z. (2015). Sosyal bilimlerde nitel araştırma yöntemleri. Sosyal Hizmet E-Dergi Manevi Temelli Sosyal Hizmet Araştırmaları Dergisi, 1 (1), 3-15.

Ling, J., Robbins, L.B., Wen, F., \& Peng, W. (2015). Interventions to increase physical activity in children aged 2-5 years: a systematic review. Pediatr Exerc Science, 27(3), 314-33. DOI:10.1123/pes.2014-0148.

Özbey, S. (2010). Okul öncesi çocuklarda uyum ve davranış problemleriyle başa çıkmada ailenin rolü. Aile ve Toplum, 6(22), 9-18.

Özdemir, Ö.S., ve Tepeli, K. (2016). Okul öncesi öğretmenlerinin saldırgan davranışlarla baş etme stratejilerinin incelenmesi. Ahi Evran Üniversitesi Kırşehir Eğitim Fakültesi Dergisi (KEFAD), 17(2), 1-70.

Pless, M., Carlsson, M., Sundelin, C., \& Persson, K. (2000). Effects of group motor skill intervention on five- to six-year-old children with developmental coordination disorder. Pediatr Phys Theraphy, 12(4),183-9.

Riethmuller, A.M., Jones, R., \& Okely, A.D. (2009). Efficacy of interventions to improve motor development in young children: a systematic review. Pediatrics, 124(4), 782-92. DOI:10.1542/peds.2009-0333

Robinson, L.E., \& Goodway, J.D. (2009). Instructional climates in preschool children who are at-risk. Part I: object-control skill development. Res $Q$ Exerc Sport, 80(3), 533-42. DOI:10.1080/02701367.2009.10599591.

Roth, K., Roth, C., \& Hegar, E. (2016). Mini top okulu erken çocukluk ve okulöncesi dönem çocuklar için oyunun ABC'si. Ankara: Harf Eğitim Yayıncılığı.

Two fingers crossing in X. form https://www.shutterstock.com/tr/image-photo/two-fingers-crossing-X-formisolated-505655167, Erişim tarihi: 27.10.2017.

Uysal, H., Altun Akbaba, S., ve Akgün, E. (2010). The Strategies preschool teachers use when confronted with children's undesired behaviors. Elementary Education Online, 9(3), 971-979. 
İlker Kerkez, F. (2018). Oyun ve motor beceri eğitimi sırasında 4 yaş çocuklarda gözlenen davranış bozukluklarının önlenmesinde çarpı stratejisinin etkisi. Spor Bilimleri Araştırmaları Dergisi, 3(1), 54-63.

Wick, K., Leeger-Aschmann, C.S., Monn, N.D., Radtke, T., Ott, L.V., Rebholz, C.E., Cruz, S., Gerber, N., et al. (2017). Interventions to promote fundamental movement skills in childcare and kindergarten: A Systematic review and meta-analysis. Sports Med, 47(10), 2045-2068. DOI:10.1007/s40279-017-0723-1.

Yıldırım, A., ve Şimşek, H. (2008). Sosyal bilimlerde nitel araştırma yöntemleri (6. Baskl). Ankara: Seçkin Yayıncilik. 